\title{
Pontocerebellar hypoplasia type 6
}

\author{
INSERM
}

\section{Source}

INSERM. (1999). Orphanet: an online rare disease and orphan drug data base.

Pontocerebellar hypoplasia type 6. ORPHA:166073

Pontocerebellar hypoplasia type 6 (PCH6) is a rare form of pontocerebellar hypoplasia (see this term) characterized clinically at birth by hypotonia, clonus, epilepsy impaired swallowing and from infancy by progressive microencephaly, spasticity and lactic acidosis. 